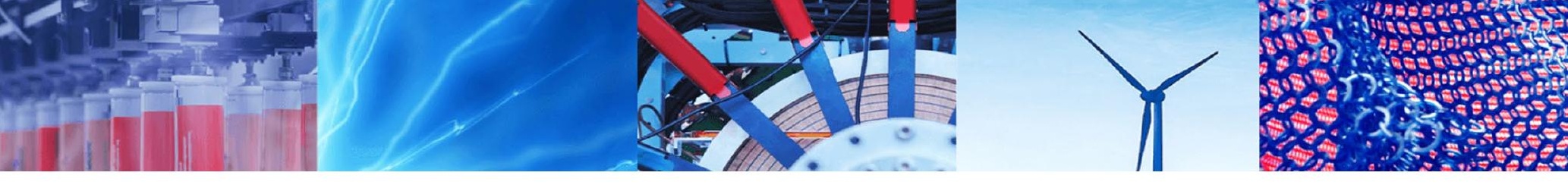

Research Article

\title{
Performance of carbonate calcium nanoparticles as filtration loss control agent of water-based drilling fluid
}

\author{
Farshad Dehghani ${ }^{1,5} \cdot$ Azim Kalantariasl $^{1,2} \cdot$ Rahmatallah Saboori $^{3} \cdot$ Samad Sabbaghi ${ }^{4} \cdot$ Kiana Peyvandi $^{5}$
}

Received: 31 May 2019 / Accepted: 7 October 2019 / Published online: 24 October 2019

(c) Springer Nature Switzerland AG 2019

\begin{abstract}
Application of nanoparticles in improvement of drilling fluid properties through effective control of fluid loss and rapid formation of thin, smooth and low permeable filter cake has gained considerable attention in recent years. In this study, calcium carbonate nanoparticle was synthesized by precipitation method and characterized by X-ray diffraction, Fourier transform infrared spectroscopy, scanning electron microscope (SEM), dynamic light scattering and Zeta-potential measurement. Water based bentonite drilling fluid was used as base fluid. Various concentrations of calcium carbonate nanoparticle (0.025-0.5 wt\%) was added to water-based drilling fluid. Fluid loss volume, filter cake thickness and its surface morphology, and rheological properties of both base fluid and fluid containing calcium carbonate nanoparticles was measured and compared. Results show that addition of calcium carbonate nanoparticle greatly affects filtration properties and forms smoother cake surface. Optimum concentration of $0.07 \mathrm{wt} \%$ calcium carbonate nanoparticle was obtained which results in reduction of fluid loss volume and filter cake thickness by $26 \%$ and $64 \%$ respectively while minor change in rheological behavior was observed. SEM image showed smoother cake surface of drilling fluid with calcium carbonate nanoparticle as additive compared to base drilling fluid. Considerable improvement in filtration properties using acid soluble $\mathrm{CaCO}_{3}$ nanoparticles can help in minimizing fluid leak-off and formation damage of producing layers and more effective well cleanup for fast oil and gas production.
\end{abstract}

Keywords Nanoparticle $\cdot$ Calcium carbonate $\cdot$ Drilling fluid $\cdot$ Fluid loss $\cdot$ Mud cake $\cdot$ Rheological properties

\section{Introduction}

Drilling fluid is a vital part of oil, gas and geothermal drilling operations. Drilling fluid consists of a base fluid (water/ oil), solid additives and chemicals. Many additives are used in drilling fluid since it has many functions including supporting formation pressure, cleaning of the wellbore, cutting transport and removal, cooling tubular, minimizing formation damage through rapid buildup of external filter cake and preventing fluid loss into the subsurface formations, etc. It is widely accepted that almost all drilling problems are directly or indirectly related to drilling fluid. Thus proper drilling fluid design is a key issue in safe and cost effective drilling operations [1-3].

Among drilling fluid functions, preventing fluid loss into the subsurface formations is very important for formation damage control, wellbore stability, and loss of fluids into the formation which can be optimized by selection of proper additives. Along filtration control, formation of thin low permeable filter cake on the well wall has critical role in reduction of fluid loss and strengthen the wellbore by minimizing contact between drilling fluid and adjacent formation through reduction of fluid loss [3-6].

$\triangle$ Azim Kalantariasl, Azim.kalantari@shirazu.ac.ir| ${ }^{1}$ Department of Petroleum Engineering, School of Chemical and Petroleum Engineering, Shiraz University, Shiraz, Iran. ${ }^{2}$ Formation Damage and Well Treatment Research Group, IOR/EOR Research Institute, Shiraz University, Shiraz, Iran. ${ }^{3}$ Department of Chemical Engineering, Lar University, Lar, Iran. ${ }^{4}$ Department of Nano Chemical Engineering, School of Advanced Technologies, Shiraz University, Shiraz, Iran. ${ }^{5}$ School of Chemical Engineering, Semnan University, Semnan, Iran. 
Nanoparticles have been proposed for wettability alteration, asphaltene deposition mitigation and removal, drilling fluid performance enhancement [7-10]. In drilling operations, they have been used for shale inhibition, fluid loss control, thermal conductivity improvement, enhancement of rheological properties [9, 11-13].

Many nanoparticles are investigated to improve drilling fluid properties in the literature. Silica nanoparticles have been employed to decrease water absorption into shale formation and reducing drilling problems such as pipe sticking, shale hydration and wellbore stability [6, 14-16]. CMC nanoparticles have been applied for rheology improvement, filter cake thickness reduction and filtration control $[9,17] . \mathrm{Fe}_{3} \mathrm{O}_{4}$ has been used for improvement of drilling fluid properties at high pressure high temperature (HPHT) conditions [18].

Invasion of drilling fluid solids and filtration of water into hydrocarbon bearing formation can result in many problems [19]. Water can change near wellbore wettability which affects oil production. Different chemistry of water may detach fine particles from grain surface and alter permeability which is a severe problem that can defer production and may not be cured in some cases. Thus minimizing formation damage is a desirable issue that can be achieved with proper mud design and additive selection [2-4].

In this study, the effect of calcium carbonate nanoparticle on filtration and rheological properties of water-based drilling fluid was investigated. Calcium carbonate nanoparticle was chosen since it is a cost-effective acid soluble particle that can be used in hydrocarbon pay zones. Calcium carbonate nanoparticle was synthesized and characterized. Then nanoparticle was added to drilling fluid and filtration and rheological properties were measured. The effect of calcium carbonate nanoparticle concentration on fluid loss, cake thickness and surface morphology, and rheological properties was investigated and optimum concentration with minimum fluid loss and cake thickness was obtained.

\section{Experimental section}

\subsection{Materials}

Sodium carbonate, calcium acetate, polyethylene glycol (PEG), and ethanol (>98\%) were purchased from Merck company. Deionized water was perched from Zolal Company. Bentonite was supplied from National Iranian Drilling Company.

\subsection{Synthesis of calcium carbonate nanoparticle}

In this study, calcium carbonate nanoparticles were synthesized by chemical precipitation method. To synthesize nanoparticle, $5 \mathrm{~g}$ of sodium carbonate and polyethylene glycol were added to $20 \mathrm{ml}$ of deionized water and stirred with a magnetic stirrer (solution A). Then $3 \mathrm{~g}$ of calcium acetate was added to $25 \mathrm{ml}$ of deionized water and the solution stirred for $40 \mathrm{~min}$ by magnetic stirrer (solution B). Solution B was added to solution A drop wise while stirring with vigorous stirring at ambient conditions. The process was completed after $2.5-3 \mathrm{~h}$ at ambient condition. Then, the product was allowed to precipitate completely. The sediment dried and then the final powder was placed in $100{ }^{\circ} \mathrm{C}$. The synthesized calcium carbonate nanoparticle was characterized using $X$-ray diffraction (XRD) and dynamic light scattering (DLS). The composition blend of sample was examined via a Unisantis XMD 300, X-ray diffract meter and systematic Xpert PRO X-ray diffraction ( $\lambda=0.17890 \mathrm{~nm}$ ). $2 \Theta$ confine used was starting $30-75$ in stages of 0.02 by enumerate time of $1 \mathrm{~s}$. The Fourier transform infrared spectroscopy (FTIR) was examined via SHIMADZU 8300 FTIR spectroscopy for bonds of synthesized calcium carbonate nanoparticle. TESCAN VEGA3 scanning electron microscope (SEM) was used to determine the morphology of synthesized nanoparticle.

In order to prepare calcium carbonate nanoparticles dispersion for zeta-potential and particle size distribution measurement, nanoparticles were gradually added to deionized water and mixed by vigorous magnetic stirrer for $30 \mathrm{~min}$ at $25^{\circ} \mathrm{C}$. Then, the suspension was sonicated by ultrasonic device with high power $(20 \mathrm{kHz}$ and $400 \mathrm{~W})$ for 30 min at $25^{\circ} \mathrm{C}$ using water bath for temperature control. It is noteworthy that no dispersant and stabilizer were used for dispersion of nanoparticles in base fluid. Size distribution of calcium carbonate nanoparticles was recorded by a Horiba-LB-550 dynamic light scattering (DLS). DLS equipment measures particle size in the rage of $1 \mathrm{~nm}$ to $6 \mu \mathrm{m}$. To evaluate the stability of calcium carbonate nanoparticles to be used in water-based drilling fluid, zeta-potential of nanofluid was measured by Microtrac zeta-check.

\subsection{Preparation of drilling fluid}

To prepare base drilling fluid, $10 \mathrm{~g}$ of bentonite powder was gradually added to $350 \mathrm{ml}$ of deionized water and mixed by Hamilton Beach mixer with 36,000 rpm for 20 min.

To prepare Nano drilling fluid, calcium carbonate nanoparticle with different concentrations was added to 
$100 \mathrm{ml}$ deionized water and mixed with magnetic stirrer for $30 \mathrm{~min}$ and then, sonicated with $20 \mathrm{kHz}$ and $300 \mathrm{~W}$ for 15 min (solution A). This process was performed to monitor stability of nanoparticles (calcium carbonate) before addition to base drilling. In addition, $10 \mathrm{~g}$ of bentonite, and $250 \mathrm{ml}$ of deionized water were mixed by Hamilton Beach Mixer for 10 min with 36,000 rpm (solution B). The solution $A$ was dropwise added to solution $B$ and mixed by Hamilton Beach Mixer for 15 min.

Filtration properties such as fluid loss and filter cake thickness of drilling fluid were measured using filter press device according to API standard. Filter press at 100 psi and $25^{\circ} \mathrm{C}$ was used for monitoring fluid loss versus time. Fluid loss was recorded every $5 \mathrm{~min}$ to compare the effect of calcium carbonate nanoparticle concentration on cumulative fluid loss. The required time to measure the fluid loss and filter cake thickness is $30 \mathrm{~min}$ as industry standard. Then optimum calcium carbonate nanoparticle was obtained. SEM of cake surface on the filter paper was taken for both base drilling fluid and drilling fluid with optimum concentration samples to compare the effects of calcium carbonate additive on cake surface. Rheology test (shear stress vs. shear rate) for base fluid and fluid with optimum concentration were also performed.

\section{Results}

\subsection{Characterization of calcium carbonate nanoparticle}

The XRD pattern of synthesized calcium carbonate nanoparticle is shown Fig. 1. The XRD analysis demonstrates the characteristic peaks at $26.5,27.7,33.4,45.9$ and $51.5^{\circ}$ corresponding to the calcium carbonate. The peaks are in good agreement with the crystalline planes of calcium carbonate nanoparticle reported in the literature [20-22]. The crystal size of the synthesized calcium carbonate nanoparticle was estimated about $40 \mathrm{~nm}$ by using the Debye-Scherrer formula.

Figure 2 shows the FTIR spectrum of synthesized calcium carbonate nanoparticle by precipitation method. The bands at 712,848 and $872 / \mathrm{cm}$ were attributed to the $\mathrm{CO}_{3}{ }^{2-}$ (calcite) vibration mode of calcium carbonate nanoparticle. The symmetric stretching vibrational of $\mathrm{CO}_{3}{ }^{2-}$ and $\mathrm{C}-\mathrm{H}$ band was observed at 1406 and $2850 / \mathrm{cm}$, respectively. Also, the bands were detected at 2513 and $2916 / \mathrm{cm}$, which indicated the calcite and C-C (mode of vibration). The bond at 1795 was assigned to the calcite vibration mode [21, 23-26].

Figure 3 shows the morphology of calcium carbonate nanoparticles. The synthesized $\mathrm{CaCO}_{3}$ consists of semispherical particles and the particle size is $<60 \mathrm{~nm}$.

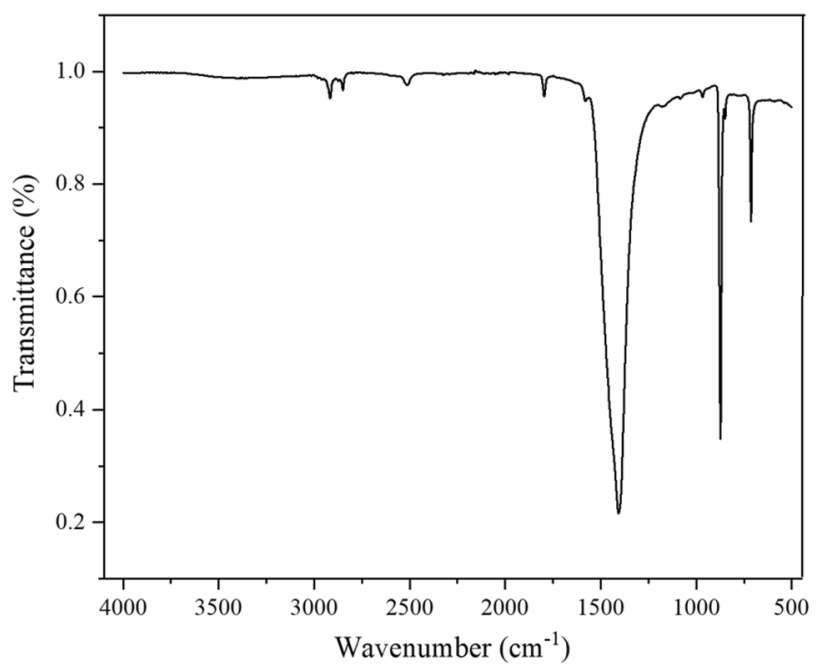

Fig. 2 FTIR analysis of synthesized calcium carbonate nanoparticle
Fig. 1 The XRD pattern of synthesized calcium carbonate nanoparticle by precipitation method

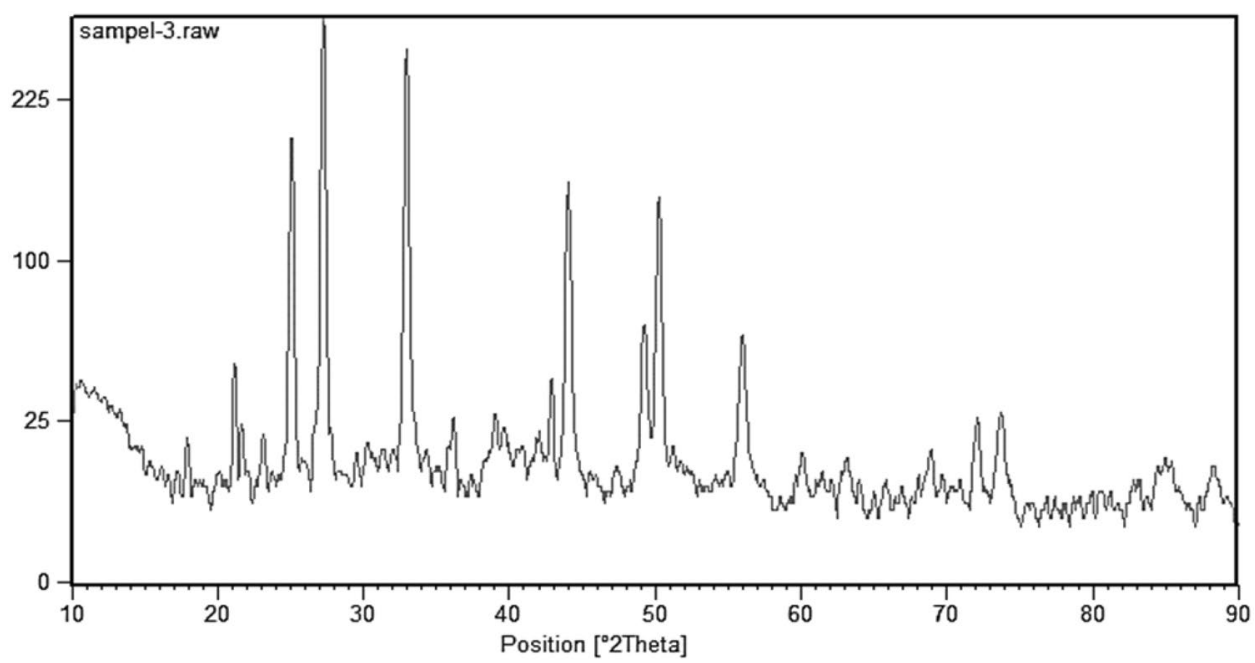

SN Applied Sciences A SPRINGER NATURE journa 


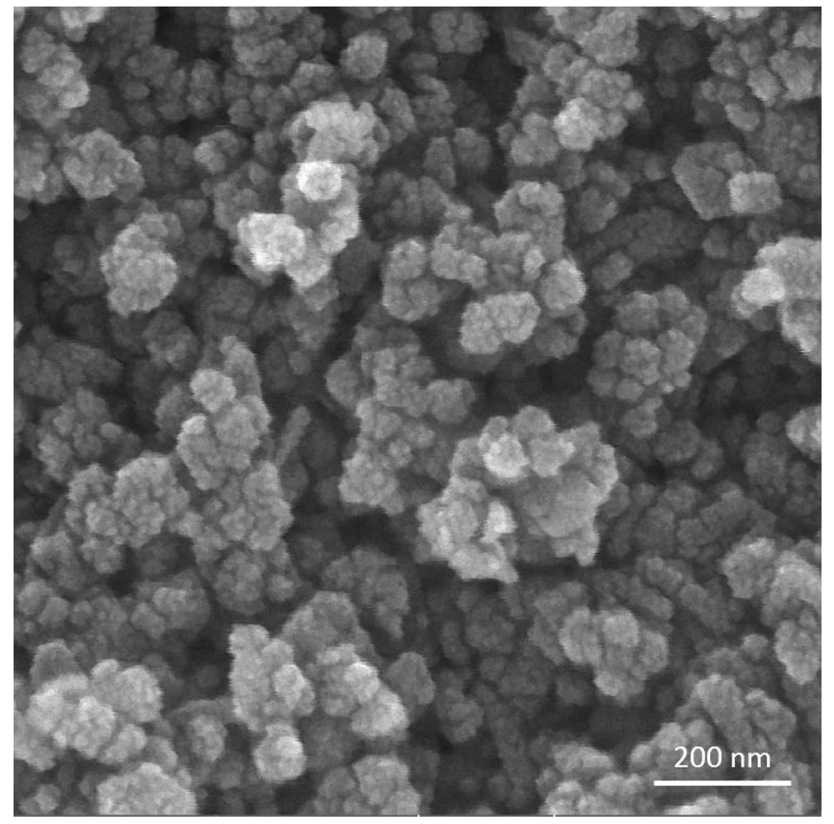

Fig. 3 FE-SEM image of calcium carbonate nanoparticle

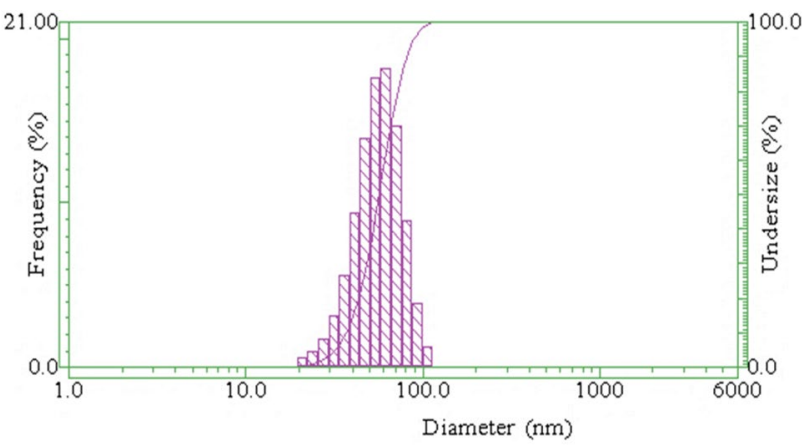

Fig. 4 Particle size distribution (DLS) of calcium carbonate nanoparticle

Figure 4 shows the particle size distribution (DLS) of synthesized calcium carbonate nanoparticle. Average particle size of nanoparticle is $55.4 \mathrm{~nm}$ and particle size distribution is narrow in water based fluid.

Table 1 shows absolute values of zeta-potential for different concentrations of calcium carbonate nanofluid in water base fluid. Nanofluids with all concentrations less than $0.15 \mathrm{wt} \%$ had excellent stability $(>60 \mathrm{mV}$ ) which confirm the stability conditions.

\section{SN Applied Sciences}

Table 1 Zeta-potential of calcium carbonate nanofluid at different concentrations

\begin{tabular}{ll}
\hline Nanofluid concentration (wt\%) & $\begin{array}{l}\text { Absolute zeta- } \\
\text { potential }(\mathrm{mV})\end{array}$ \\
\hline 0.025 & 73.0 \\
0.050 & 68.0 \\
0.070 & 66.3 \\
0.150 & 63.8 \\
0.500 & 55.5 \\
\hline
\end{tabular}

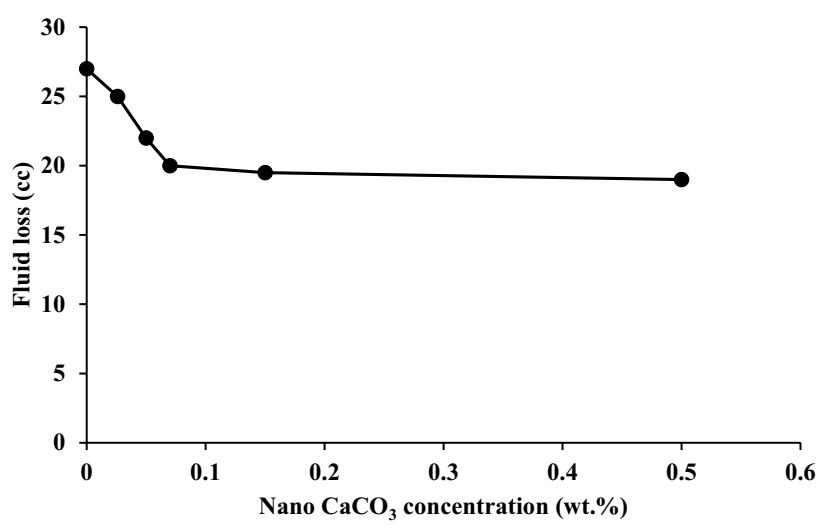

Fig. 5 Effect of nano $\mathrm{CaCO}_{3}$ concentration on fluid loss (30 min)

\subsection{Characterization of drilling fluid}

\subsubsection{Drilling fluid filtration test}

The effect of calcium carbonate nanoparticle concentration on fluid loss is shown in Fig. 5. Filtration for $30 \mathrm{~min}$ at 100 psi pressure and measuring fluid loss volume via filter press device which is standard in drilling industry is presented for different calcium carbonate nanoparticle concentrations. Increase in nanoparticle concentration from $0.025-0.07 \mathrm{wt} \%$ causes sharp decrease in fluid loss from 27 to $20 \mathrm{cc}$. from 0.07 to $0.5 \%$, the change in fluid loss is not significant. It shows $26 \%$ decrease in fluid loss volume just by addition of $0.07 \%$ calcium carbonate nanoparticle which is considerable in large volume of drilling fluid used daily in oil and gas drilling operations.

Figure 6 shows the effect of calcium carbonate nanoparticle concentration on cumulative fluid loss (total fluid loss during $30 \mathrm{~min}$ filtration) that has been recorded every $5 \mathrm{~min}$.

Regarding calcium carbonate nanoparticle concentration effect, highest cumulative fluid loss corresponds to 0.025 wt $\%$ while for $0.07,0.15$ and $0.5 \mathrm{wt} \%$ the cumulative fluid loss are almost the same which confirms 


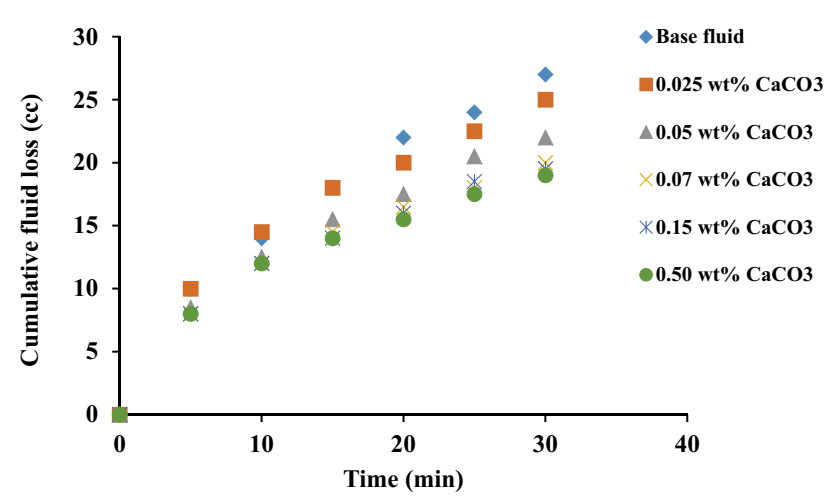

Fig. 6 Cumulative fluid loss in the presence of different concentration of calcium carbonate nanoparticle versus time

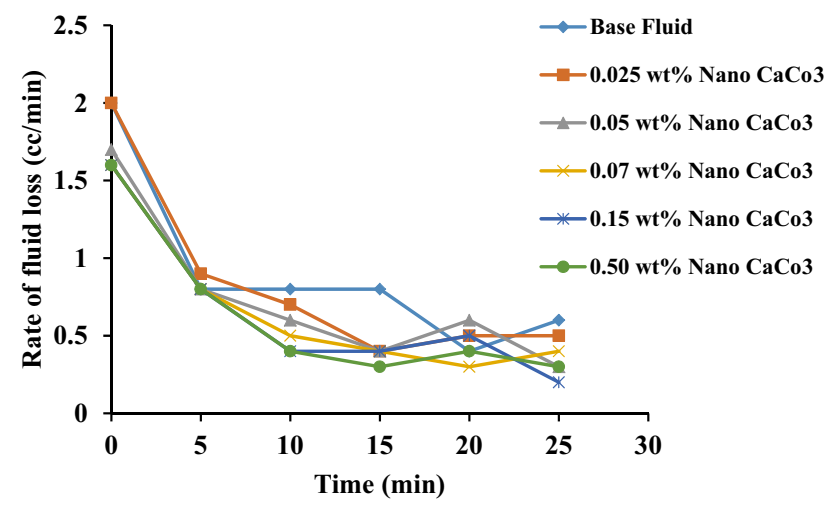

Fig. 7 Rate of fluid loss in the presence of different concentration of nano $\mathrm{CaCO}_{3}$

good performance of calcium carbonate nanoparticle at desired concentrations.

Initial rate of fluid loss (during 5 min interval) for base mud (without calcium carbonate nanoparticle), 0.025 and $0.05 \mathrm{wt} \%$ calcium carbonate nanoparticle are 2 , 2 and $1.7 \mathrm{cc} / \mathrm{min}$ respectively while for $0.07,0.15$, and $0.5 \mathrm{wt} \%$ is $1.6 \mathrm{cc} / \mathrm{min}$ which shows $20 \%$ decrees in rate of fluid loss at initial filtration time. Less fluid loss rate corresponds to better cake formation which is desired in drilling operations.

Figure 7 presents rate of fluid loss (derivative of cumulative fluid loss vs. time, Fig. 6) as a function of time for base fluid and different calcium carbonate nanoparticle concentrations.

In order to better demonstrate the effect of nano $\mathrm{CaCO}_{3}$ concentration on rate of fluid loss, Fig. 8 shows fluid rate in whole time span (derivative of cumulative fluid loss vs. time but not local time as presented in Fig. 6) and the effect of calcium carbonate nanoparticle concentration on rate of fluid loss is significant both for initial fluid loss rate and rate versus time.

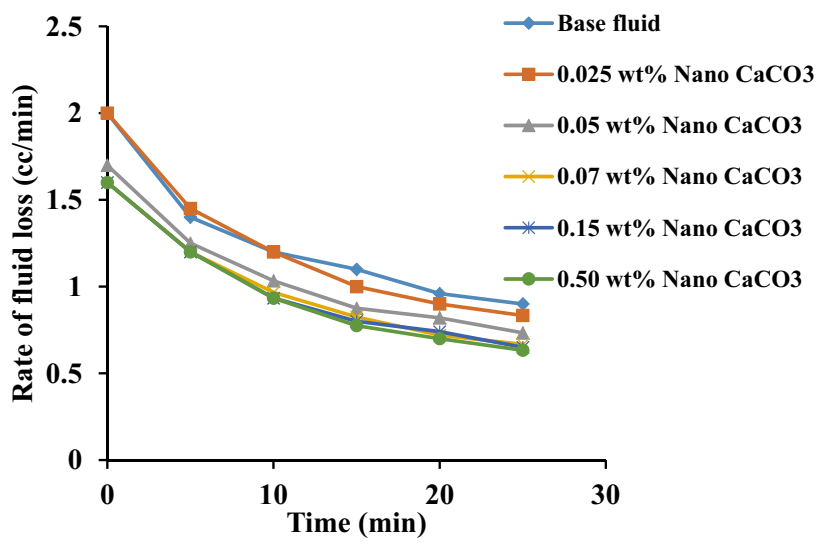

Fig. 8 Rate of fluid loss in the presence of different concentration of calcium carbonate nanoparticle for whole time span

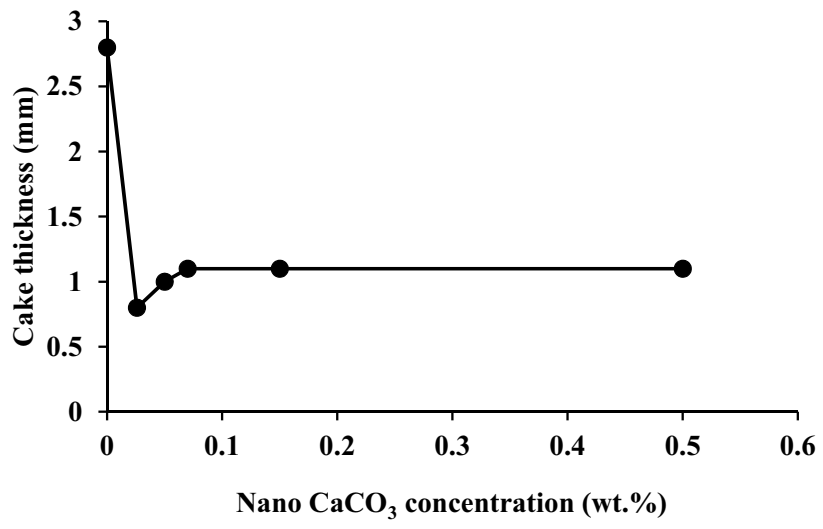

Fig. 9 Thickness of mud cake in the presence of nano $\mathrm{CaCO}_{3}$ in drilling fluid

It should be mentioned that, all experiments were repeated three times and the average of results is reported here.

\subsubsection{Filter cake properties}

Cake thickness Cake thickness plays an important role in drilling operations of oil, gas and geothermal wells. Formation of thin and low permeable external filter cake on the wall of the formation is crucial for minimization of fluid loss into the adjacent formation, strengthen and stability of the borehole, and reducing risk of pipe sticking. Figure 9 shows filter cake thickness obtained for different concentrations of calcium carbonate nanoparticle added to the base drilling fluid. It shows that addition of small amount of calcium carbonate nanoparticle significantly reduced cake thickness (from $2.8 \mathrm{~mm}$ to almost $1 \mathrm{~mm}$ ). It seems that on average and considering fluid loss results (Fig. 5), an optimum concentration of $0.07 \mathrm{wt} \%$ calcium carbonate 
nanoparticle results in $26 \%$ decrease in fluid loss and $64 \%$ decrease in cake thickness which is a great achievement both from economical and operational aspects. Thus, optimum conditions can be achieved considering both fluid loss volume and cake thickness during 30 min filtration.

Cake surface The morphology of mud cake surface after filtration test and drying is shown in Fig. 10. SEM Image of base drilling fluid (without carbonate calcium nanoparticle) is presented in Fig. 10a. Figure 10b shows SEM image of cake surface using 0.07 wt $\%$ calcium carbonate nanoparticle. It shows more homogenous and smoother surface compared to cake surface of base drilling fluid.

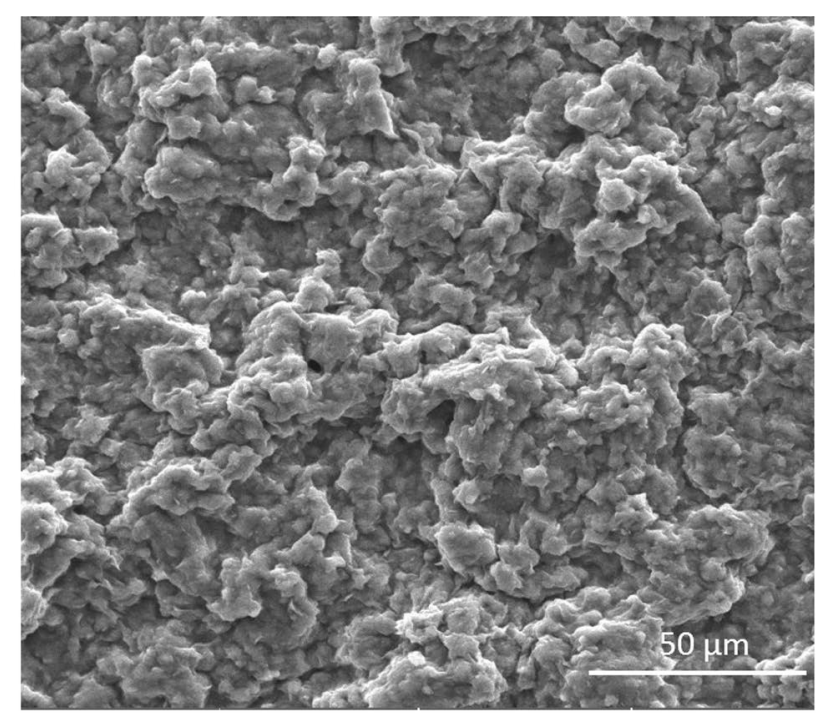

(a)

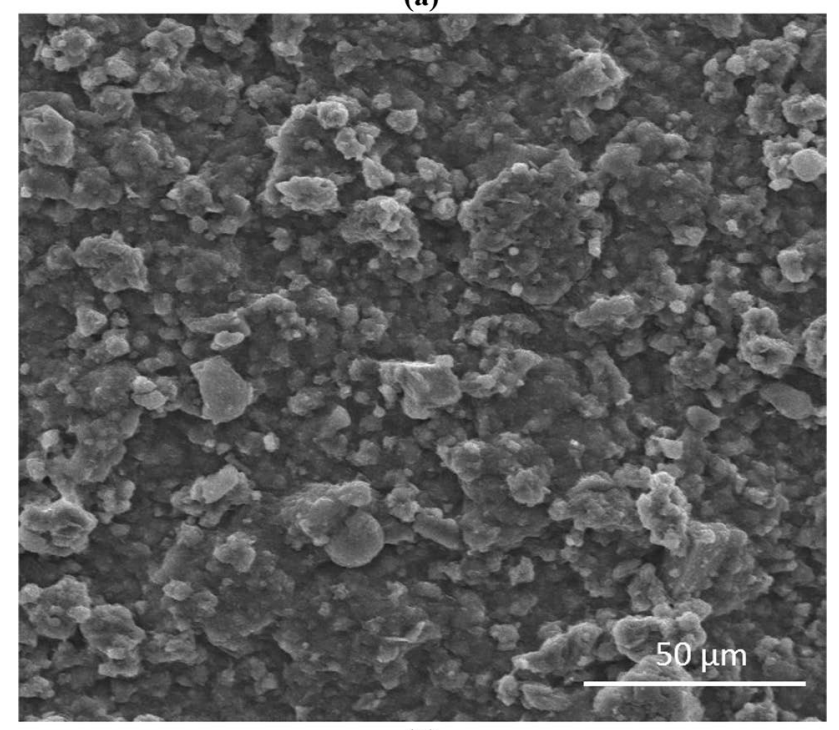

(b)

Fig. 10 SEM image of a water-based drilling fluid without nanoparticle, b water-based drilling fluid with $0.07 \mathrm{wt} \%$ of calcium carbonate nanoparticle
Addition of nanoparticle can improve cake formation quality with filling small pores and making smoother cake surface. It results in less fluid filtration and subsequent thinner cake formation which both are desirable drilling fluid properties for drilling operations. It is favorable to form a low permeable cake at early time of filtration since it reduces fluid loss and consequently thin cake can be formed in dynamic drilling fluid filtration.

\subsubsection{Rheological test}

Rheological behavior of $0.07 \mathrm{wt} \%$ calcium carbonate nanoparticle concentration and base drilling fluid is presented in Fig. 11. It shows Bingham plastic model for both fluids which is typical for drilling fluid. One can see that despite improvement in filtration and cake thickness, rheological behavior does not change significantly that may be due to low concentration of calcium carbonate nanoparticle needed for such an improvement. It is noteworthy that, the calcium carbonate nanoparticles used in this study have no effect on the mud density and $\mathrm{pH}$ of drilling fluid for all concentrations.

\section{Discussion}

Filtrate-loss volumes are used to compare the performance of various fluid types in drilling industry. The proposed nano-particle in this paper shows promising results to be used in water-based drilling fluid as fluid loss control. Reduction of fluid filtration into underground formations greatly affects economic of drilling operations. Moreover small cake thickness is desirable in drilling operations since it greatly reduces pipe sticking and consequently non-operating time of drilling rig. This is very important in drilling of horizontal wells where pipe sticking is more likely to happen frequently.

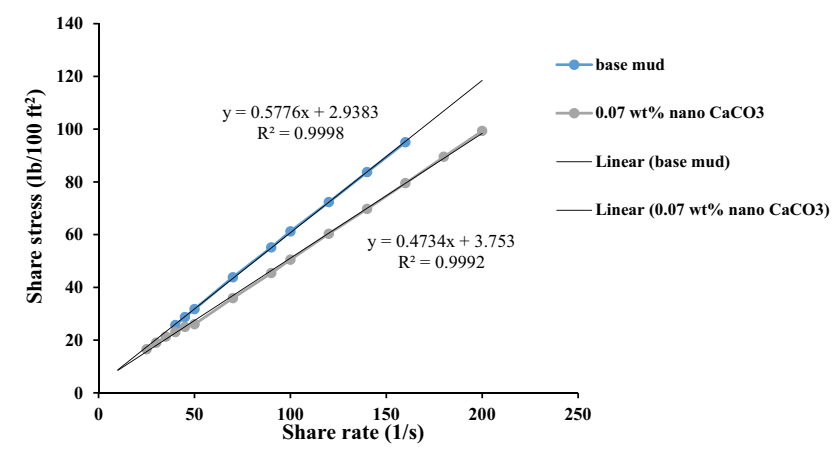

Fig. 11 Rheological behavior of $0.07 \mathrm{wt} \%$ calcium carbonate nanoparticle and base drilling fluid 
The performance of nano $\mathrm{CaCO}_{3}$ can be compared with existing filtration control agents. Filtration control is critical for drilling pay zones (formations containing oil/gas) to minimize fluid leak-off and formation damage. It is very common to use acid soluble $\mathrm{CaCO}_{3}$ particles as fluid loss control additive when drilling oil and gas producing formations since after drilling it is required to remove filter cake from the wall of the well bore (well clean up) for oil and gas production. Thus using nano$\mathrm{CaCO}_{3}$ in drilling reservoir sections is superior to other agents due to promising performance in filtration (less filtrate, thin and smoother cake) and its solubility in $\mathrm{HCl}$.

Static and dynamic filtration of proposed nano-particle using core plugs from target formation in core-flooding system can be used to evaluate its performance in desired pressure and temperature conditions [3]. Moreover, using real core sample from different formations allows obtaining filtration performance of proposed nano particle in more realistic conditions.

Elemental analysis of filter cake surface can improve our understanding of performance of additives. Visual observation of cake surface and layers using micro computed-tomography (CT) scanning can give insights about mechanisms behind performance of nano $\mathrm{CaCO}_{3}$ in drilling fluid $[27,28]$.

\section{Conclusions}

Carbonate calcium nanoparticle was synthesized via precipitation method and characterized by XRD, FTIR, SEM, DLS and zeta-potential measurement and the synthesized nanoparticles were used as filtration reducer in water-based drilling fluid.

- Fluid loss was considerably reduced with addition of carbonate calcium nanoparticles.

- Optimum concentration of carbonate calcium nanoparticle $(0.07 \mathrm{wt} \%)$ results in $26 \%$ decrease in fluid loss and $64 \%$ reduction of cake thickness.

- SEM image of cake surface confirmed smoother cake surface when using carbonate calcium nanoparticle as drilling fluid additive.

\section{Compliance with ethical standards}

Conflict of interest The authors declare that they have no conflict of interest.

\section{References}

1. Bourgoyne AT, Millheim KK, Chenevert ME, Young F (1986) Applied drilling engineering. SPE Textbook Series. Society of Petroleum Engineers, Richardson

2. Ezeakacha CP, Salehi S (2018) Experimental and statistical investigation of drilling fluids loss in porous media-part 1. J Nat Gas Sci Eng 51:104-115. https://doi.org/10.1016/j.jngse .2019.03.007

3. Kalantariasl A, Zeinijahromi A, Bedrikovetsky P (2014) External filter cake buildup in dynamic filtration: mechanisms and key factors. In: SPE international symposium and exhibition on formation damage control society of petroleum engineers. https://doi.org/10.2118/168144-MS

4. Civan F (2015) Reservoir formation damage. Gulf Professional Publishing, Houston

5. Ezeakacha CP, Salehi S, Bi HA (2018) New approach to characterize dynamic drilling fluids invasion profiles in application to near-wellbore strengthening effect. In: IADC/SPE drilling conference and exhibition. Society of Petroleum Engineers. https://doi.org/10.2118/189596-MS

6. Sensoy T, Chenevert ME, Sharma MM (2009) Minimizing water invasion in shales using nanoparticles. In: SPE annual technical conference and exhibition. Society of Petroleum Engineers. https://doi.org/10.2118/124429-MS

7. Ahmadi R, Osfouri S, Azin R (2018) Wettability alteration of carbonate oil reservoir surface using biocompatible nanoparticles. Mater Res Express 6:025033. https://doi. org/10.1088/2053-1591/aaee57

8. Panahi S, Sardarian AR, Esmaeilzadeh F, Mowla D (2018) Synthesize and characterization of chitosan and silica supported on $\mathrm{Fe}_{3} \mathrm{O}_{4}$ nanoparticles for the adsorption and removal of asphaltene molecules from crude oil. Mater Res Express 5:095022. https://doi.org/10.1088/2053-1591/aad7ae

9. Saboori R, Sabbaghi S, Kalantariasl A, Mowla D (2018) Improvement in filtration properties of water-based drilling fluid by nanocarboxymethyl cellulose/polystyrene core-shell nanocomposite. J Pet Explor Prod Technol 8:445-454. https:// doi.org/10.1007/s13202-018-0432-9

10. Sakhaei Z, Azin R, Naghizadeh A, Osfouri S, Saboori R, Vahdani $H$ (2018) Application of fluorinated nanofluid for production enhancement of a carbonate gas-condensate reservoir through wettability alteration. Mater Res Express 5:035008. https://doi.org/10.1088/2053-1591/aab176

11. Aftab A, Ismail A, Khokhar S, Ibupoto ZH (2016) Novel zinc oxide nanoparticles deposited acrylamide composite used for enhancing the performance of water-based drilling fluids at elevated temperature conditions. J Pet Sci Eng 146:11421157. https://doi.org/10.1016/j.petrol.2016.08.014

12. Rafati R, Smith SR, Haddad AS, Novara R, Hamidi H (2018) Effect of nanoparticles on the modifications of drilling fluids properties: a review of recent advances. J Pet Sci Eng 161:6176. https://doi.org/10.1016/j.petrol.2017.11.067

13. Saboori R, Sabbaghi S, Barahoei M, Sahooli M (2017) Improvement of thermal conductivity properties of drilling fluid by CuO nanofluid. Transp Phenom Nano Micro Scales 5:97-101. https://doi.org/10.7508/TPNMS.2017.02.003

14. Cai J, Chenevert ME, Sharma MM, Friedheim JE (2012) Decreasing water invasion into Atoka shale using nonmodified silica nanoparticles. SPE Drill Complet 27:103-112. https://doi. org/10.2118/146979-PA

15. Huang X, Sun J, Lv K, Liu J, Shen H, Zhang F (2018) Application of core-shell structural acrylic resin/nano- $\mathrm{SiO}_{2}$ composite in water based drilling fluid to plug shale pores. J Nat Gas Sci Eng 55:418-425. https://doi.org/10.1016/j.jngse.2018.05.023 
16. Villada Y, Gallardo F, Erdmann E, Casis N, Olivares L, Estenoz D (2017) Functional characterization on colloidal suspensions containing xanthan gum (XGD) and polyanionic cellulose (PAC) used in drilling fluids for a shale formation. Appl Clay Sci 149:5966. https://doi.org/10.1016/j.clay.2017.08.020

17. Saboori R, Sabbaghi S, Mowla D, Soltani A (2012) Decreasing of water loss and mud cake thickness by CMC nanoparticles in mud drilling. Int J Nano Dimens 3:101-104. https://doi. org/10.7508/IJND.2012.02.002

18. Mahmoud O, Nasr-El-Din HA, Vryzas Z, Kelessidis V (2018) Effect of ferric oxide nanoparticles on the properties of filter cake formed by calcium bentonite-based drilling muds. SPE Drill Complet. https://doi.org/10.2118/184572-PA

19. Salmachi A, Talemi P, Tooski ZY (2016) Psyllium husk in waterbased drilling fluids: an environmentally friendly viscosity and filtration agent. In: Abu Dhabi international petroleum exhibition and conference. Society of Petroleum Engineers. https:// doi.org/10.2118/183308-ms

20. Huber M, Stark WJ, Loher S, Maciejewski M, Krumeich F, Baiker A (2005) Flame synthesis of calcium carbonate nanoparticles. Chem Commun. https://doi.org/10.1039/b419099h

21. Islam KN, Bakar MZBA, Ali ME, Hussein MZB, Noordin MM, Loqman M, Miah G, Wahid H, Hashim U (2013) A novel method for the synthesis of calcium carbonate (aragonite) nanoparticles from cockle shells. Powder Technol 235:70-75. https://doi. org/10.1016/j.powtec.2012.09.041

22. Kato T, Sugawara A, Hosoda N (2002) Calcium carbonateorganic hybrid materials. Adv Mat 14:869-877. https://doi. org/10.1002/1521-4095(20020618)14
23. Zhang Z, Xie Y, Xu X, Pan H, Tang R (2012) Transformation of amorphous calcium carbonate into aragonite. J Cryst Growth 343(1):62-67. https://doi.org/10.1016/j.jcrysgro.2012.01.025

24. Wang F, Ge HH, Wu K, Wang LT, Wan C, Sha JY, Zhao YZ (2019) Effects of $\mathrm{Al}_{2} \mathrm{O}_{3}$ nanoparticles on the crystallization of calcium carbonate in aqueous solution. J Nanosci Nanotechnol 19(6):3471-3478. https://doi.org/10.1166/jnn.2019.16132

25. Li M, Mann S (2002) Emergent nanostructure:water-induced mesoscale transformation of surfactant-stabilized amorphous calcium carbonate nanoparticle in revers microemulsions. Adv Funct Mater 12(11-12):773-779. https://doi.org/10.1002/ adfm.200290006

26. Kamba AS, Ismail M, Ibrahim TAT, Zakaria ZAB (2013) Synthesis and characterisation of calcium carbonate aragonite nanocrystals from cockle shell powder (Anadara granosa). J Nanomater. https://doi.org/10.1155/2013/398357

27. Saboori R, Sabbaghi S, Kalantariasl A (2019) Improvement of rheological, filtration and thermal conductivity of bentonite drilling fluid using copper oxide/polyacrylamide nanocomposite. Powder Technol 353:257-266. https://doi.org/10.1016/j.powte c.2019.05.038

28. Orlov MS, Roschin PV, Struchkov IA, Litvin VT (2015) The application of X-ray micro computed tomography (micro-ct) of core sample for estimation of physicochemical treatment efficiency. In: SPE Russian petroleum technology conference. Society of Petroleum Engineers. https://doi.org/10.2118/176600-ms

Publisher's Note Springer Nature remains neutral with regard to jurisdictional claims in published maps and institutional affiliations. 